Article

\title{
Effect of Heating Rate on Pyrolysis Behavior and Kinetic Characteristics of Siderite
}

\author{
Xiaolong Zhang *, Yuexin Han *, Yanjun Li and Yongsheng Sun \\ College of Resources and Civil Engineering, Northeastern University, Shenyang 110819, China; \\ liyanjun@mail.neu.edu.cn (Y.L.); yongshengsun@mail.neu.edu.cn (Y.S.) \\ * Correspondence: zhangxiaolong0530@163.com (X.Z.); dongdafulong@mail.neu.edu.cn (Y.H.)
}

Received: 10 October 2017; Accepted: 1 November 2017; Published: 3 November 2017

\begin{abstract}
The pyrolysis characteristics of siderite at different heating rates under the neutral atmosphere were investigated using various tools, including comprehensive thermal analyzer, tube furnace, $\mathrm{X}$-ray diffraction (XRD), scanning electron microscope (SEM), energy-dispersive spectrometry (EDS) and vibrating specimen magnetometer (VSM) measurements. The reaction of siderite pyrolysis followed the one-step reaction under the neutral atmosphere: $\mathrm{FeCO}_{3} \rightarrow \mathrm{Fe}_{3} \mathrm{O}_{4}+\mathrm{CO}_{2}+\mathrm{CO}$. As the increasing of heating rate, the start and end pyrolysis temperatures and temperate where maximum weight loss rate occurred increased, while the total mass loss were essentially the same. Increasing heating rate within a certain range was in favor of shortening the time of each reaction stage, and the maximum conversion rate could be reached with a short time. The most probable mechanism function for non-isothermal pyrolysis of siderite at different heating rates was $\mathrm{A}_{1 / 2}$ reaction model (nucleation and growth reaction). With increasing heating rate, the corresponding activation energies and the pre-exponential factors increased, from 446.13 to $505.19 \mathrm{~kJ} \cdot \mathrm{mol}^{-1}$, and from $6.67 \times 10^{-18}$ to $2.40 \times 10^{-21}$, respectively. All siderite was transformed into magnetite with a porous structure after pyrolysis, and some micro-cracks were formed into the particles. The magnetization intensity and specific susceptibility increased significantly, which created favorable conditions for the further effective concentration of iron ore.
\end{abstract}

Keywords: siderite; neutral atmosphere; heating rate; pyrolysis; mechanism

\section{Introduction}

China is rich in siderite resources, which are difficult to exploit by traditional beneficiation methods. The development of efficient utilization technology for siderite can increase the reserves of available iron ore, improve the tight situation of iron ore supply, and ensure the iron ore security of China. Magnetization roasting followed by magnetic separation was the most effective technology for the exploitation and utilization of siderite resources [1-4]. During the process, the siderite could be transformed to a highly magnetic mineral phase, while the magnetism of gangue minerals was barely changed, benefiting magnetic separation of the iron minerals and gangue minerals effectively [5-9]. The pyrolysis behavior and kinetic characteristics are important to better understand and further improve the magnetization roasting for siderite.

Many studies have focused on the pyrolysis mechanism, including the conversion process, pyrolysis product characteristics and pyrolysis kinetics in the process of siderite magnetization roasting. It was found that the phase transformation process in weak oxidizing atmosphere followed the steps as: $\mathrm{FeCO}_{3} \rightarrow \mathrm{Fe}_{3} \mathrm{O}_{4} \rightarrow \gamma-\mathrm{Fe}_{2} \mathrm{O}_{3}$ at $550{ }^{\circ} \mathrm{C}$, and $\mathrm{FeCO}_{3} \rightarrow \mathrm{FeO}+\mathrm{Fe}_{3} \mathrm{O}_{4} \rightarrow \mathrm{Fe}_{3} \mathrm{O}_{4} \rightarrow \gamma-\mathrm{Fe}_{2} \mathrm{O}_{3} \rightarrow \alpha-\mathrm{Fe}_{2} \mathrm{O}_{3}$ at $800{ }^{\circ} \mathrm{C}$. In inert atmosphere, the decomposition pathway was: $\mathrm{FeCO}_{3} \rightarrow \mathrm{Fe}_{3} \mathrm{O}_{4}$ below $733{ }^{\circ} \mathrm{C}$, and $\mathrm{FeCO}_{3} \rightarrow \mathrm{FeO}+\mathrm{Fe}_{3} \mathrm{O}_{4}$ above $733{ }^{\circ} \mathrm{C}$ [10]. The final product was $\alpha-\mathrm{Fe}_{2} \mathrm{O}_{3}$ under the oxygen flow, and it was $\mathrm{Fe}_{3} \mathrm{O}_{4}$ in a $\mathrm{CO}_{2}$ atmosphere, while the $\mathrm{FeO}$ and $\mathrm{Fe}_{3} \mathrm{O}_{4}$ were only observed in an 
inert atmosphere [11-13]. Geva et al. [14] concluded the potassium markedly increased the reduction rate of wustite and changed the iron properties in subsequent reduction. $\mathrm{Mn}$ and $\mathrm{Mg}$ impurities existed in natural siderite as isomorphism state with iron and thereby influenced the decomposition process [15]. The chemical and physical characteristics of siderite before and after decomposition change tremendously. The phase transformation and microstructure were extremely complex related to atmosphere, temperature, heating rate, and its characteristics [16-19]. However, there has been little systematic and theoretical research on the influence of the heating rate on siderite decomposition.

The pyrolysis kinetics of siderite ore was studied that the mechanism of siderite pyrolysis process was applicable to each particle size interval, while the pyrolysis kinetics differed under different atmospheres [20]. The pyrolysis mechanism for magnesium-manganese siderite was investigated, it was demonstrated the mechanism function was F1, with activation energy of $192 \mathrm{~kJ} \cdot \mathrm{mol}^{-1}$ [21]. In air atmosphere, the Avrami-Erofe'ev reaction mechanism could explicate the pyrolysis kinetics of siderite, where the isothermal pyrolysis kinetics of siderite obeyed the nucleation and growth mechanism $(n=1)$, and the activation energy and the pre-exponential factor $(\ln A)$ were $46.17 \mathrm{~kJ} \cdot \mathrm{mol}^{-1}$ and $23.02 \mathrm{~min}^{-1}$, respectively [22]. The pyrolysis kinetics of siderite in suspended state from Wangjiatan of Shanxi Province in China was conducted by Feng et al. [23] under different isothermal conditions. The result indicated that the mechanism function was R3 (phase boundary reaction), and the pyrolysis process was accelerated with increasing temperature. Most researchers have studied the pyrolysis kinetics of siderite by an isothermal approach, not verified by a non-isothermal method. Moreover, the isothermal method is difficult to implement completely in the laboratory, especially at the beginning of the reaction.

Consequently, it is necessary to study the pyrolysis mechanism and kinetic characteristics of siderite at different heating rates to further understand siderite pyrolysis behavior, and may have implication for exploitation of Fe-bearing carbonates as a source of iron ore.

\section{Experimental}

\subsection{Materials}

The bulky iron ore rich in siderite from Hunan Province of China was used in this study. The sample was crushed through a roller crusher and ground to $85 \%$ passing $0.074 \mathrm{~mm}$, then the pure siderite minerals was obtained via the gravity process using a shaking table and a low-intensity magnetic separator. The chemical composition (Table 1) indicated that the most valuable element was iron, with iron grade of $44.21 \%$ and $\mathrm{FeO}$ content up to $58.05 \%$. It also contained $1.19 \% \mathrm{MgO}$ and $2.53 \%$ MnO. Harmful elements such as sulfur, phosphorus and sodium were minor. The iron mineral analysis results (Table 2) showed that iron mainly existed in form of carbonate iron $(96.23 \%)$, indicating that siderite was the major mineral in the sample. The sample belonged to high-quality pure siderite, which could satisfy the experiments well.

Table 1. Chemical composition of pure siderite mineral (in mass \%).

\begin{tabular}{lllllllcccc}
\hline $\mathrm{Fe}_{\text {total }}$ & $\mathrm{FeO}$ & $\mathrm{SiO}_{2}$ & $\mathrm{Al}_{2} \mathrm{O}_{3}$ & $\mathrm{CaO}$ & $\mathbf{M g O}$ & $\mathbf{N a}$ & $\mathbf{M n O}$ & $\mathbf{P}$ & $\mathbf{S}$ & Loss of Ignition \\
\hline 44.21 & 58.05 & 0.55 & 0.13 & 0.30 & 1.19 & 0.01 & 2.53 & undetected & 0.34 & 36.04 \\
\hline
\end{tabular}

Table 2. Iron mineral analysis of pure siderite mineral (in mass \%).

\begin{tabular}{cccccc}
\hline Iron Phases & Iron Carbonate & Magnetite & Hematite & Iron Sulfide & Ferrosilite \\
\hline Iron \% & 39.45 & 0.12 & 3.69 & 0.85 & 0.10 \\
Mineral \% & 96.23 & 0.27 & 2.35 & 0.92 & 0.23 \\
\hline
\end{tabular}




\subsection{Methods}

\subsubsection{Pyrolysis Behavior Analysis of Siderite}

The thermal decomposition was conducted by non-isothermal pyrolysis analysis using a comprehensive thermal analyzer (STA449-F3, Netzsch, Hamburg, Germany). Nitrogen (99.99\%) was used as protection gas, which could restrain the diffusion effect of carbon dioxide from siderite pyrolysis. A $30 \mathrm{mg}$ sample was used for each experiment at a nitrogen flow rate of $30 \mathrm{~mL} / \mathrm{min}$. The heating rates studied were $5,10,20$ and $30^{\circ} \mathrm{C} \cdot \mathrm{min}^{-1}$. The temperature range was from room temperature to $900{ }^{\circ} \mathrm{C}$, and the thermogravimetry (TG), derivative thermogravimetry (DTG), and differential scanning calorimetry (DSC) analysis results were obtained from computer processor.

\subsubsection{Pyrolysis Kinetics Characteristics of Siderite at Different Heating Rates}

The conversion fraction $\alpha$ based on the TG analysis results can be expressed as:

$$
\alpha=\frac{m_{0}-m_{t}}{m_{0}-m_{\infty}}
$$

where $m_{0}$ is the initial sample mass $(\mathrm{g}), m_{t}$ is the sample mass at a particular time $(\mathrm{g})$, and $m_{\infty}$ is the theoretical weight loss (g).

The conversion rate $\mathrm{r}$ can be calculated:

$$
\mathrm{r}=\frac{d \alpha}{d t}=\frac{\Delta \alpha}{\Delta t}
$$

where $\Delta \alpha$ is the weight loss in a short span of time $(\mathrm{g})$, and $\Delta t$ is the short time interval (min).

Non-isothermal study of pyrolysis kinetics has great advantages compared with isothermal one. A non-isothermal thermal analysis curve often contains more information and function than isothermal analysis curves, which can make the analysis quickly and comprehensive. The differential isothermal kinetics equation of solid-state decomposition can be described by the following well-known general equation [24-29]:

$$
\frac{d \alpha}{d t}=A \exp ^{-E / R T} \cdot f(\alpha)
$$

where $E$ is the activation energy $\left(\mathrm{kJ} \cdot \mathrm{mol}^{-1}\right), A$ is the pre-exponential factor, $T$ is the temperature (Kelvin, $\mathrm{K}), t$ is the time ( $\mathrm{min}), R$ is the gas constant $\left(8.314 \mathrm{~J} \cdot(\mathrm{mol} \cdot \mathrm{K})^{-1}\right)$, and $f(\alpha)$ is the differential conversion function.

Some modifications are adopted in the non-isothermal kinetics compared with isothermal one. Introducing the heating rate $\left(\beta=d T / d t\right.$, where $\beta$ is heating rate, $\left.{ }^{\circ} \mathrm{C} \cdot \mathrm{min}^{-1}\right)$, the reaction rate for a heterogeneous reaction are presented by the following well-known general equation [30]:

$$
\frac{d \alpha}{d t}=\beta \frac{d \alpha}{d T}=A \exp ^{-E / R T} \cdot f(\alpha)
$$

By rearranging and integrating Equation (4), the integral form of mechanism function $(G(\alpha))$ can be obtained:

$$
\mathrm{G}(\alpha)=\int_{0}^{T}\left(\frac{A}{\beta}\right) \exp ^{-E / R T} d T
$$

Kinetic analysis is expected to obtain an adequate kinetic description of the process in terms of kinetic parameters (the reaction model, the activation energy, and the pre-exponential factor) [31]. Many methods have been established to evaluate these parameters. The Flynn-Wall-Ozawa (FWO) method based on integral isoconversional methods has been widely used to lucubrate thermodynamics [32]. By the 
application of Doyle's method [33,34], the activation energy $(E)$ can be determined as a function of the temperatures corresponding to fixed values from experiments at different heating rates:

$$
\lg (\beta)=\lg \left(\frac{A E}{R G(\alpha)}\right)-2.315-0.4567 \frac{E}{R T}
$$

The most probable mechanism function can be determined by Šatava-Šesták integral method, which is given as follow [35]:

$$
\lg G(\alpha)=\lg \left(\frac{A E_{S}}{R \beta}\right)-2.315-0.4567 \frac{E_{S}}{R T}
$$

The most probable mechanism function can be determined by analyzing the linear relationship between $\lg (G(\alpha))$ and $1 / T$. If only one $G(\alpha)$ meets the linear relationship, the $G(\alpha)$ is exactly the mechanism function. However, if several $G(\alpha)$ meet the linear relationship, the $G(\alpha)$, whose activation energy $\left(E_{S}\right)$ is approximately equal to the activation energy $(E)$ estimated by FWO method, is the most probable mechanism function [31]. The activation energy $E$ and the pre-exponential factor $A$, and correlation coefficient $R$ can be derived from the linear least-squares plot of $\lg (G(\alpha))$ versus $1 / T$.

Siderite pyrolysis reaction is the typical gas-solid reaction. Based on previous studies, the most frequently-used reaction mechanism models of gas-solid reaction are listed in Table 3 [36-39].

\begin{tabular}{|c|c|c|c|c|}
\hline Code & Reaction Model & Mechanism & Integral $\mathrm{G}(\alpha)$ & Differential $f(\alpha)$ \\
\hline $\mathrm{A}_{1 / 3}$ & Avrami-Erofeev $(n=1 / 3)$ & \multirow{10}{*}{$\begin{array}{l}\text { Nucleation and } \\
\text { growth }\end{array}$} & {$[-\ln (1-\alpha)]^{3}$} & $1 / 3(1-\alpha)[-\ln (1-\alpha)]^{-2}$ \\
\hline $\mathrm{A}_{1 / 2}$ & Avrami-Erofeev $(n=1 / 2)$ & & {$[-\ln (1-\alpha)]^{2}$} & $1 / 2(1-\alpha)[-\ln (1-\alpha)]^{-1}$ \\
\hline $\mathrm{A}_{2 / 3}$ & Avrami-Erofeev $(n=2 / 3)$ & & {$[-\ln (1-\alpha)]^{3 / 2}$} & $2 / 3(1-\alpha)[-\ln (1-\alpha)]^{-1 / 2}$ \\
\hline $\mathrm{A}_{1}$ & Avrami-Erofeev $(n=1)$ & & $-\ln (1-\alpha)$ & $1-\alpha$ \\
\hline $\mathrm{A}_{4 / 3}$ & Avrami-Erofeev $(n=4 / 3)$ & & {$[-\ln (1-\alpha)]^{3 / 4}$} & $4 / 3(1-\alpha)[-\ln (1-\alpha)]^{1 / 4}$ \\
\hline $\mathrm{A}_{3 / 2}$ & Avrami-Erofeev $(n=3 / 2)$ & & {$[-\ln (1-\alpha)]^{2 / 3}$} & $3 / 2(1-\alpha)[-\ln (1-\alpha)]^{1 / 3}$ \\
\hline $\mathrm{A}_{2}$ & Avrami-Erofeev $(n=2)$ & & {$[-\ln (1-\alpha)]^{1 / 2}$} & $2(1-\alpha)[-\ln (1-\alpha)]^{1 / 2}$ \\
\hline $\mathrm{A}_{5 / 2}$ & Avrami-Erofeev $(n=5 / 2)$ & & {$[-\ln (1-\alpha)]^{2 / 5}$} & $5 / 2(1-\alpha)[-\ln (1-\alpha)]^{3 / 5}$ \\
\hline $\mathrm{A}_{3}$ & Avrami-Erofeev $(n=3)$ & & {$[-\ln (1-\alpha)]^{1 / 3}$} & $3(1-\alpha)[-\ln (1-\alpha)]^{2 / 3}$ \\
\hline $\mathrm{A}_{4}$ & Avrami-Erofeev $(n=4)$ & & {$[-\ln (1-\alpha)]^{1 / 4}$} & $4(1-\alpha)[-\ln (1-\alpha)]^{3 / 4}$ \\
\hline $\mathrm{D}_{1}$ & & $\begin{array}{c}\text { One-dimensional } \\
\text { diffusion }\end{array}$ & $\alpha^{2}$ & $1 / 2 \alpha^{-1}$ \\
\hline $\mathrm{D}_{2}$ & Valensi & $\begin{array}{l}\text { Two-dimensional } \\
\text { diffusion }\end{array}$ & $\alpha+(1-\alpha) \ln (1-\alpha)$ & {$[-\ln (1-\alpha)]^{-1}$} \\
\hline $\mathrm{D}_{3}$ & Jander & \multirow{6}{*}{$\begin{array}{c}\text { Three-dimensional } \\
\text { diffusion }\end{array}$} & {$[1-(1-\alpha) 1 / 2]^{2}$} & $(1-\alpha)^{1 / 2}[1-(1-\alpha) 1 / 2]^{-1}$ \\
\hline $\mathrm{D}_{4}$ & Jander $(n=2)$ & & {$[1-(1-\alpha) 1 / 3]^{2}$} & $3 / 2(1-\alpha)^{2 / 3}[1-(1-\alpha) 1 / 3]^{-1}$ \\
\hline $\mathrm{D}_{5}$ & Jander $(n=1 / 2)$ & & {$[1-(1-\alpha) 1 / 3]^{1 / 2}$} & $6(1-\alpha)^{2 / 3}[1-(1-\alpha) 1 / 3]^{1 / 2}$ \\
\hline $\mathrm{D}_{6}$ & anti-Jander & & {$\left[(1+\alpha)^{1 / 3}-1\right]^{2}$} & $3 / 2(1+\alpha)^{2 / 3}\left[(1+\alpha)^{1 / 3}-1\right]^{-1}$ \\
\hline $\mathrm{D}_{7}$ & Z-L-T & & {$\left[(1-\alpha)^{-1 / 3}-1\right]^{2}$} & $3 / 2(1-\alpha)^{4 / 3}\left[(1-\alpha)^{-1 / 3}-1\right]^{-1}$ \\
\hline $\mathrm{D}_{8}$ & Ginstling-Brounshtein & & $1-2 \alpha / 3-(1-\alpha)^{2 / 3}$ & $3 / 2\left[(1-\alpha)^{-1 / 3}-1\right]^{-1}$ \\
\hline $\mathrm{R}_{1 / 2}$ & Contraction sphere $(n=1 / 2)$ & \multirow{6}{*}{$\begin{array}{c}\text { Phase boundary } \\
\text { reaction }\end{array}$} & $1-(1-\alpha)^{2}$ & $1 / 2(1-\alpha)^{-1}$ \\
\hline $\mathrm{R}_{1 / 3}$ & Contraction sphere $(n=1 / 3)$ & & $1-(1-\alpha)^{3}$ & $1 / 3(1-\alpha)^{-2}$ \\
\hline $\mathrm{R}_{1 / 4}$ & Contraction sphere $(n=1 / 4)$ & & $1-(1-\alpha)^{4}$ & $1 / 4(1-\alpha)^{-3}$ \\
\hline $\mathrm{R}_{2}$ & Contraction sphere $(n=2)$ & & $1-(1-\alpha)^{1 / 2}$ & $2(1-\alpha)^{1 / 2}$ \\
\hline $\mathrm{R}_{3}$ & Contraction sphere $(n=3)$ & & $1-(1-\alpha)^{1 / 3}$ & $3(1-\alpha)^{2 / 3}$ \\
\hline $\mathrm{R}_{4}$ & Contraction sphere $(n=4)$ & & $1-(1-\alpha)^{1 / 4}$ & $4(1-\alpha)^{3 / 4}$ \\
\hline $\mathrm{P}_{2 / 3}$ & Mampel power law $(n=2 / 3)$ & & $\alpha^{3 / 2}$ & $2 / 3 \alpha^{-1 / 2}$ \\
\hline $\mathrm{P}_{1}$ & Mampel power law $(n=1)$ & & $\alpha$ & 1 \\
\hline $\mathrm{P}_{2}$ & Mampel power law $(n=2)$ & & $\alpha^{1 / 2}$ & $2 \alpha^{1 / 2}$ \\
\hline $\mathrm{P}_{3}$ & Mampel power law $(n=3)$ & & $\alpha^{1 / 3}$ & $3 \alpha^{2 / 3}$ \\
\hline $\mathrm{P}_{4}$ & Mampel power law $(n=4)$ & & $\alpha^{1 / 4}$ & $4 \alpha^{3 / 4}$ \\
\hline $\mathrm{C}_{1}$ & Reaction order $(n=2)$ & \multirow{3}{*}{ Chemical reaction } & $(1-\alpha)^{-1}-1$ & $(1-\alpha)^{2}$ \\
\hline $\mathrm{C}_{2}$ & Reaction order $(n=3 / 2)$ & & $(1-\alpha)^{-1 / 2}$ & $2(1-\alpha)^{3 / 2}$ \\
\hline $\mathrm{C}_{3}$ & Reaction order $(n=3)$ & & $(1-\alpha)^{-2}$ & $1 / 2(1-\alpha)^{3}$ \\
\hline
\end{tabular}

Table 3. Gas-solid reaction models with corresponding mechanism and function [36-39]. 


\subsubsection{The Characteristics of Siderite both before and after Pyrolysis}

The pyrolysis products of siderite derived from comprehensive thermal analyzer were only tiny amounts, which was not available for further detection and analysis. The laboratory type tube furnace (Figure 1) was employed for the study of pyrolysis test. The tests were conducted on the temperature range from room temperature to $600{ }^{\circ} \mathrm{C}$ (based on TG/DTG/DSC analysis results), with the heating rate at $10{ }^{\circ} \mathrm{C} \cdot \mathrm{min}^{-1}$ and the flow rate of nitrogen gas was $500 \mathrm{~mL} \cdot \mathrm{min}^{-1}$. The phases, microstructures and magnetic properties analysis of siderite both before and after pyrolysis were investigated by X-ray diffraction (XRD, PW3040, PANalytical B.V., Almero, The Netherlands), scanning electron microscope (SEM, SSX-550, SHIMADZU, Kyoto, Japan), energy-dispersive spectrometry (EDS, SSX-550, SHIMADZU, Kyoto, Japan) and vibrating specimen magnetometer (VSM, JDAW-2000D, YingPu Magnetic Technology Development, Changchun, China) measurements.

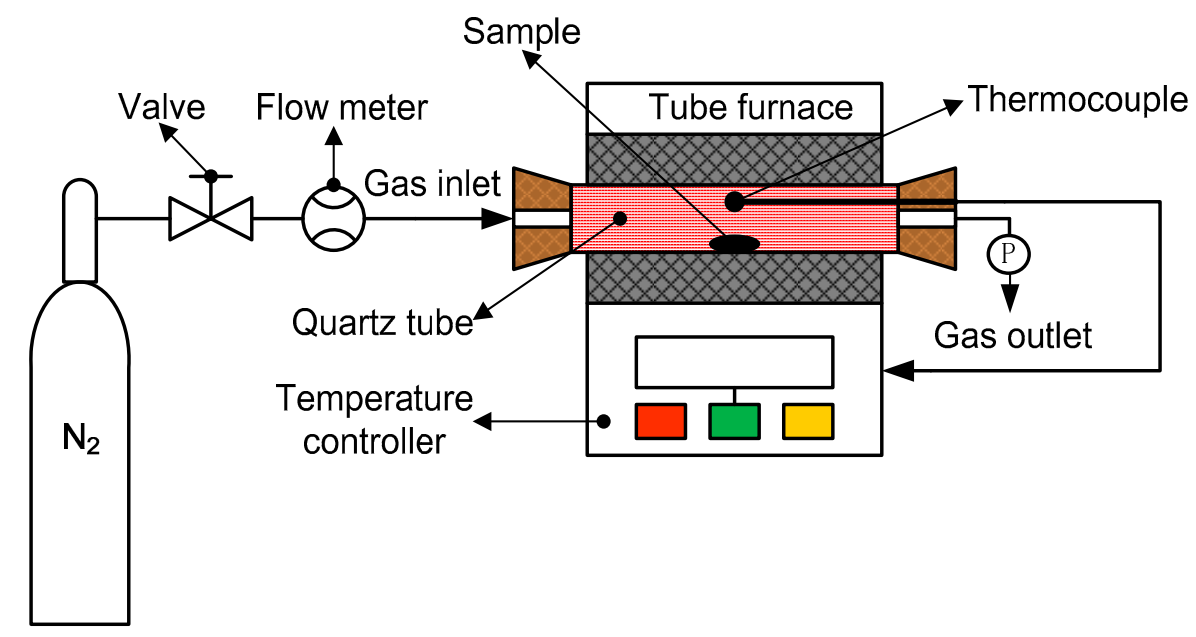

Figure 1. Schematic experimental apparatus.

\section{Results and Discussion}

\subsection{Decomposition Behavior of Siderite}

In the neutral atmosphere of pyrolysis, $\mathrm{FeO}$ emerged immediately during the decomposition of siderite, but the $\mathrm{FeO}$, as an intermediate phase, would transform to $\mathrm{Fe}_{3} \mathrm{O}_{4}$ easily in a short period of time. The reactions can be represented as:

$$
\begin{gathered}
\mathrm{FeCO}_{3} \rightarrow \mathrm{FeO}+\mathrm{CO}_{2} \Delta \mathrm{G}_{\mathrm{T}}{ }^{\theta}=74893-180.77 \mathrm{~T}, \mathrm{~J} \cdot \mathrm{mol}^{-1} \\
\mathrm{FeO}+1 / 3 \mathrm{CO}_{2} \rightarrow 1 / 3 \mathrm{Fe}_{3} \mathrm{O}_{4}+1 / 3 \mathrm{CO} \Delta \mathrm{G}_{\mathrm{T}}{ }^{\theta}=-35380+40.16 \mathrm{~T}, \mathrm{~J} \cdot \mathrm{mol}^{-1}
\end{gathered}
$$

According to Equations (8) and (9), the pyrolysis process of siderite in the neutral atmosphere can be expressed with the following equation:

$$
\mathrm{FeCO}_{3} \rightarrow 1 / 3 \mathrm{Fe}_{3} \mathrm{O}_{4}+2 / 3 \mathrm{CO}_{2}+1 / 3 \mathrm{CO} \Delta \mathrm{G}_{\mathrm{T}}{ }^{\theta}=68995-164.79 T, \mathrm{~J} \cdot \mathrm{mol}^{-1}
$$

The results of the TG/DTG/DSC analyses in the neutral atmosphere with the heating rate of $10{ }^{\circ} \mathrm{C} \cdot \mathrm{min}^{-1}$ are shown in Figure 2. Throughout the decomposition process of siderite, a minute mass loss $(-0.83 \%)$ appeared at about $250{ }^{\circ} \mathrm{C}$, corresponding to a tiny endothermic peak, which was most likely due to the moisture evaporation in the sample. The pyrolysis of siderite started at about $470{ }^{\circ} \mathrm{C}(\mathrm{Ts})$ with a maximum pyrolysis rate at about $500{ }^{\circ} \mathrm{C}(\mathrm{Tm})$. A significant endothermic peak was observed at $510{ }^{\circ} \mathrm{C}$ indicating that the pyrolytic reaction of siderite was an intense endothermic process, and the enthalpy change was $-563.3 \mathrm{~J} \cdot \mathrm{g}^{-1}$. The mass remained unchanged basically at about 
$580{ }^{\circ} \mathrm{C}(\mathrm{Te})$, which suggested the completion of the pyrolytic reaction of siderite, with the total mass loss was $33.15 \%$. The steps of mass loss on the TG curve corresponding to the peaks of the DTG/DSC curves belonged to the single and overlap-free peaks, indicating that the pyrolytic of siderite was one-step reaction (Reaction (9)).

The results of TG/DTG analysis at different heating rates are illustrated in Figure 3. It can be seen that both TG and DTG profiles shifted toward the direction of higher temperature based on the increase in thermal lag. Furthermore, the TG curves inosculated with DTG curves, and the mass loss steps of the TG curves corresponded to the peaks of the DTG curves. The starting temperature (Ts), maximum weight loss rate $(\mathrm{Tm})$ and ending temperature $(\mathrm{Te})$ increased with the increasing of heating rate, and the pyrolysis temperature range became wider. However, heating rate had little effect on the total mass loss.

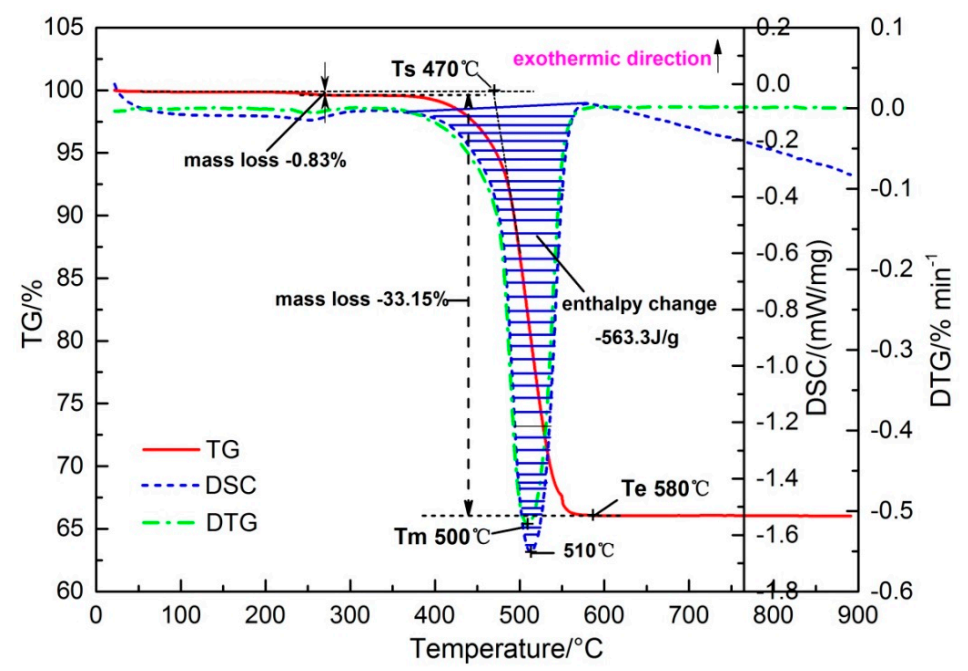

Figure 2. TG-DTG-DSC profiles of siderite sample in the neutral atmosphere.

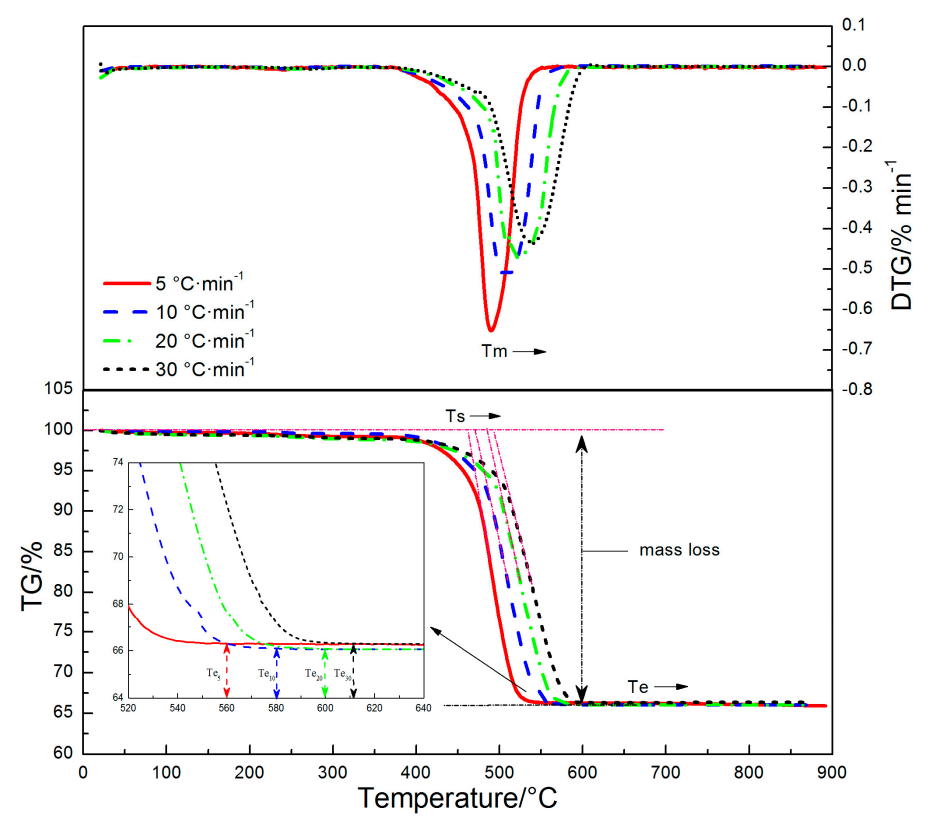

Figure 3. TG/DTG profiles of the siderite sample at different heating rates. 


\subsection{Pyrolysis Kinetics Characteristics of Siderite at Different Heating Rates}

The conversion fraction $(\alpha)$ and conversion rate $(r)$ at the different heating rates are shown in Figure 4 . At the different heating rates, all conversion fractions $(\alpha)$ of siderite exhibited three stages, i.e., initial stage, middle stage and final stage. The curves of conversion fractions at the different heating rates did not changed significantly when $\alpha$ ranged from 0 to 0.1 , which showed the stage was the initial stage of the reaction. When $\alpha$ was between 0.1 and 0.9 , the profiles rose linearly, indicating that the stage was the main reaction period of siderite pyrolysis with a great significance on the pyrolysis process of siderite. Thus the following study of pyrolysis kinetics parameters was determined for this stage. When $\alpha$ ranged from 0.9 to 1.0 , the value of conversion fractions converged to 1.0, meaning that the stage was the end of the reaction (Figure 4a).

At different heating rates, all conversion rate $(\gamma)$ curves reached a peak value from 0 , and then dropped to 0 in the end. The peak value was increased significantly with an increasing heating rate. Consequently, the heating rate had a great impact on the conversion rate. The times to reach the peak conversion rate were 95, 50, 26 and $18 \mathrm{~min}$, at the different heating rates of 5, 10, 20 and $30{ }^{\circ} \mathrm{C} \cdot \mathrm{min}^{-1}$, respectively. It was found that increasing heating rate within a certain range was in favor of siderite conversion, and the peak conversion rate could be obtained in a short time (Figure $4 \mathrm{~b}$ ).
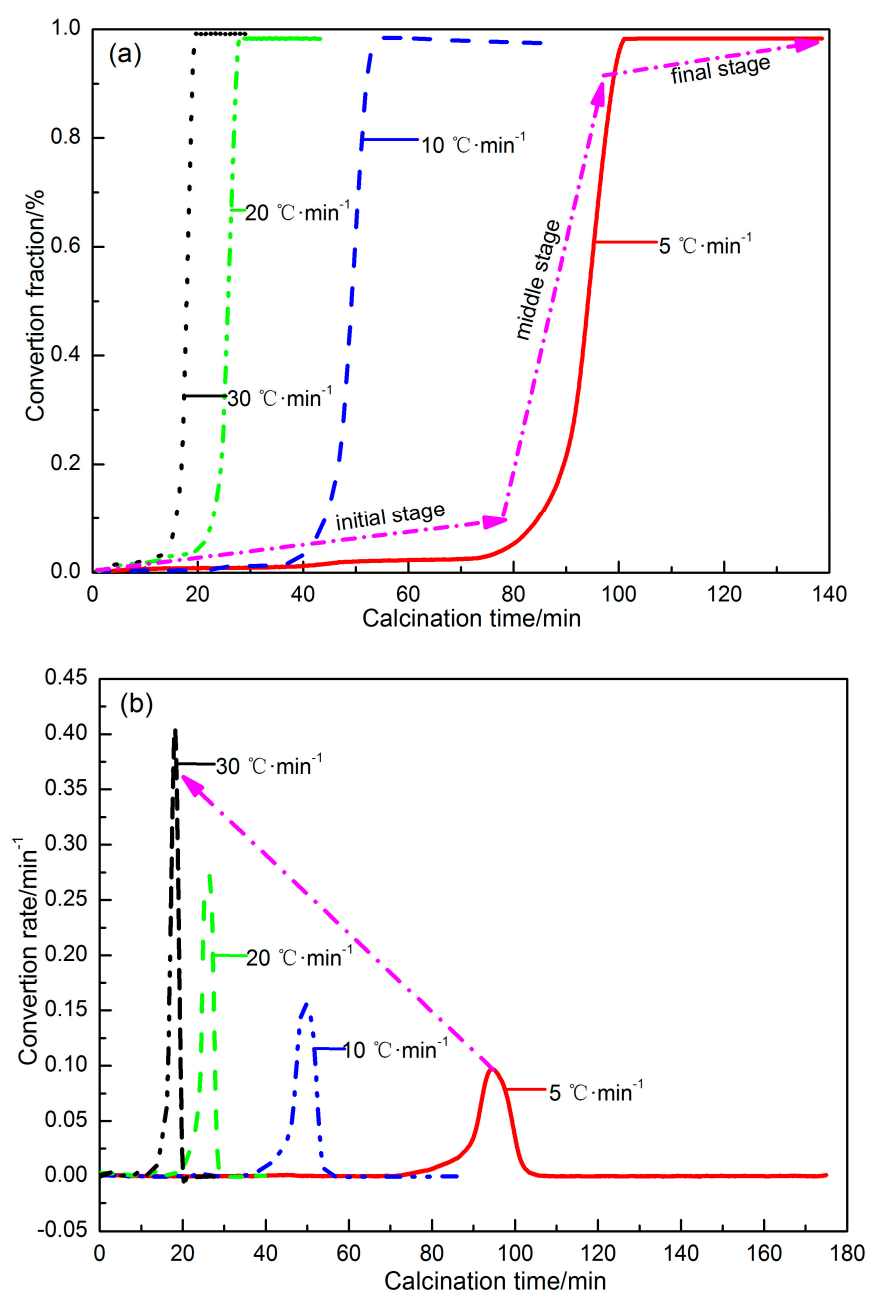

Figure 4. The conversion fraction (a) and conversion rate (b) profiles of siderite pyrolysis at different heating rates.

At each heating rate, conversion fraction $(\alpha)$ selected from 0.1 to 0.9 with an increment of 0.1 were used to calculate the activation energy using Equation (6). The $\lg (\beta)$ versus $1 / T$ plots calculated for the 
different heating rates are presented in Figure 5. From the slope of these lines in Figure 5, the $E$ value can be determined at various conversion fraction $\alpha$, as presented in Table 4 .

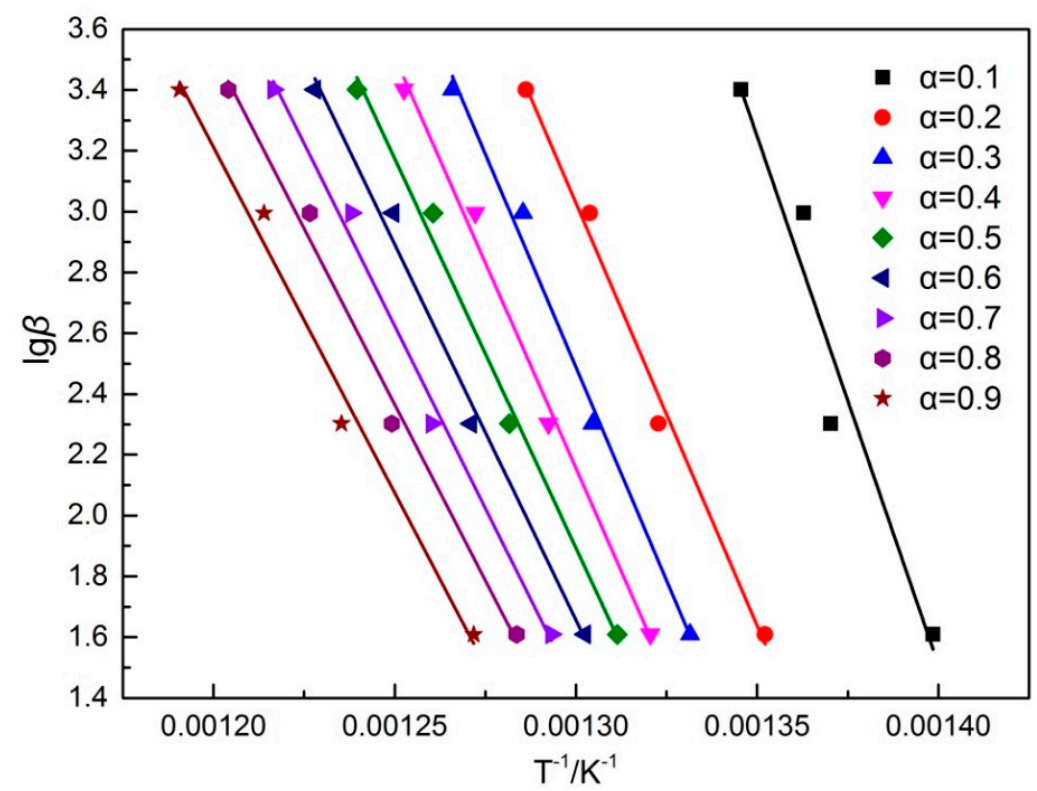

Figure 5. Regression lines for various conversion fraction based on FWO method.

Table 4. Activation energies estimated by FWO method at different conversion fraction.

\begin{tabular}{ccc}
\hline Conversion Fraction/ $\mathbf{\alpha}$ & $\boldsymbol{E} / \mathbf{k J} \cdot \mathbf{m o l}^{\mathbf{- 1} \mathbf{a}}$ & $\boldsymbol{R}^{\mathbf{b}}$ \\
\hline 0.1 & 532.65 & 0.978 \\
0.2 & 516.05 & 0.988 \\
0.3 & 510.97 & 0.989 \\
0.4 & 492.93 & 0.990 \\
0.5 & 466.63 & 0.989 \\
0.6 & 450.20 & 0.988 \\
0.7 & 436.79 & 0.989 \\
0.8 & 421.32 & 0.987 \\
0.9 & 413.92 & 0.982 \\
Average & 471.27 & 0.987 \\
\hline
\end{tabular}

${ }^{\mathbf{a}}$ E-activation energy, calculated by Equation (6); ${ }^{\mathbf{b}} R$-correlation coefficient.

As seen in Table 4, unmistakably, there was good linearity between $\lg (\beta)$ and $1 / T$ at the different conversion fraction. The activation energy $(E)$ of the siderite pyrolysis could be calculated from the corresponding slopes according to the FWO kinetic method. The average activation energy $(E)$ was $471.27 \mathrm{~kJ} \mathrm{~mol}^{-1}$.

The linear fitting results and relate kinetic parameters are summarized by Šatava-Šesták method. The calculated correlation coefficients $(R)$ using mechanism function (Table 3 ) indicated that the linearity of $\mathrm{G}(\alpha)$ for $\mathrm{A}_{1 / 2}$ reaction model versus $1 / T$ was excellent (Table 5 ); meanwhile, the activation energies of $A_{1 / 2}$ reaction model were approximately equal to those (Table 4) estimated by FWO method. Therefore it was concluded that $\mathrm{A}_{1 / 2}$ reaction model, namely, $G(\alpha)=[-\ln (1-\alpha)]^{-2}$ and $f(\alpha)=1 / 2(1-\alpha)[-\ln (1-\alpha)]^{-1}$, was the most probable mechanism function of non-isothermal pyrolysis of siderite, and the corresponding mechanism was nucleation and growth. It was found that the activation energy $(E)$ and pre-exponential factor $(A)$ increased with increasing heating rate. For instance, the activation energy $(E)$ and pre-exponential factor $(A)$ increased from $446.13 \mathrm{~kJ} \cdot \mathrm{mol}^{-1}$ to $6.67 \times 10^{-18}$ to $505.19 \mathrm{~kJ} \cdot \mathrm{mol}^{-1}$ and $2.40 \times 10^{-21}$, respectively, as heating rate increased from 5 to $30^{\circ} \mathrm{C} \cdot \mathrm{min}^{-1}$. More generally, the $A$ value reflects the degree of collisions of a reaction per minute. 
Therefore, the higher $A$ value connotes the easier occurrence of siderite pyrolysis reaction, indicating that heating rate plays a positive role in the pyrolysis process of siderite.

Table 5. Kinetic parameters to most probable mechanism function at different heating rate.

\begin{tabular}{|c|c|c|c|c|c|c|}
\hline $\begin{array}{l}\text { Heating Rate } \\
\left({ }^{\circ} \mathrm{C} \cdot \mathrm{min}^{-1}\right)\end{array}$ & Code & Intercept & Slope & $R$ & $\begin{array}{l}\text { Activation Energy } \\
E_{S}{ }^{a}\left(\mathrm{~kJ} \cdot \mathrm{mol}^{-1}\right)\end{array}$ & $\begin{array}{c}\text { Pre-Exponential } \\
\text { Factor } A^{b}\left(\min ^{-1}\right)\end{array}$ \\
\hline 5 & \multirow{4}{*}{$\mathrm{A}_{1 / 2}$} & -24506.71 & 20.54 & 0.9980 & 446.13 & $6.67 \times 10^{-18}$ \\
\hline 10 & & -25768.30 & 20.98 & 0.9993 & 469.10 & $1.75 \times 10^{-19}$ \\
\hline 20 & & -26800.51 & 22.01 & 0.9990 & 487.89 & $1.80 \times 10^{-20}$ \\
\hline 30 & & -27750.87 & 23.15 & 0.9995 & 505.19 & $2.40 \times 10^{-21}$ \\
\hline
\end{tabular}

${ }^{\mathbf{a}} E_{s}$-activation energy, calculated by Equation (7); ${ }^{\mathbf{b}} A$ - pre-exponential factor, calculated by Equation (7).

\subsection{The Characteristics of Siderite both before and after Pyrolysis}

The XRD pattern of the product obtained from the tube furnace test is shown in Figure 6. All siderite was transformed into magnetite after pyrolysis, and no other mineral phases were observed.

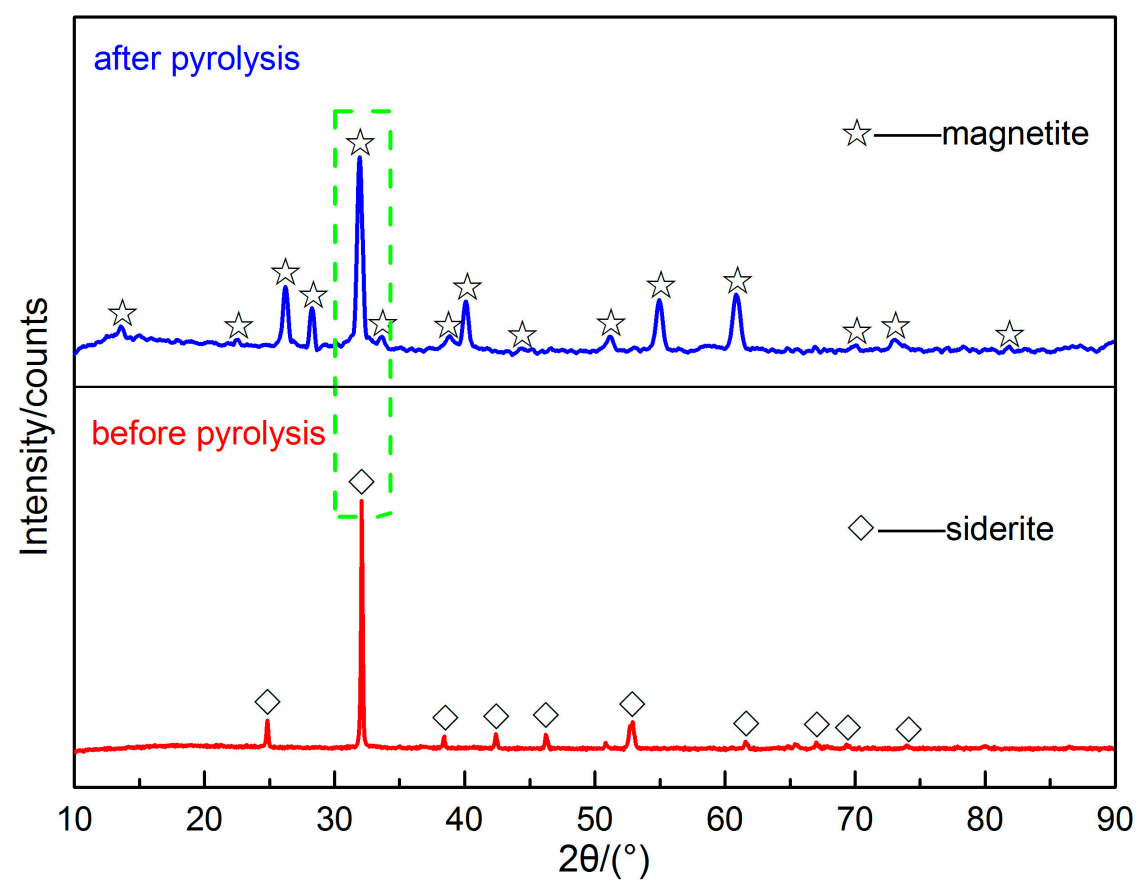

Figure 6. XRD patterns of the siderite before and after pyrolysis.

The morphologic features of the pyrolysis product from SEM and EDS analyses are shown in Figure 7. Before pyrolysis, the siderite samples were mostly chunky, with relatively even and smooth surfaces. Fe, C, O, Mn and Mg were also found on the surfaces (Figure 7a), which is in a good agreement with chemical analysis in Table 1. After pyrolysis, the surface of the newly generated magnetite appeared porous (Figure $7 \mathrm{~b}$ ), and micro-cracks were formed into the particles (Figure 7c). The carbon composition disappeared, which was most likely due to the $\mathrm{CO}_{2}$ evaporated from the samples in the process of pyrolysis. The magnetite particles with structures of pores and micro-cracks were easy to break, which could improve the grinding efficiency drastically. On the other hand, Mn and $\mathrm{Mg}$ remained in samples after pyrolysis, which could lower the iron grade of the concentrate. 

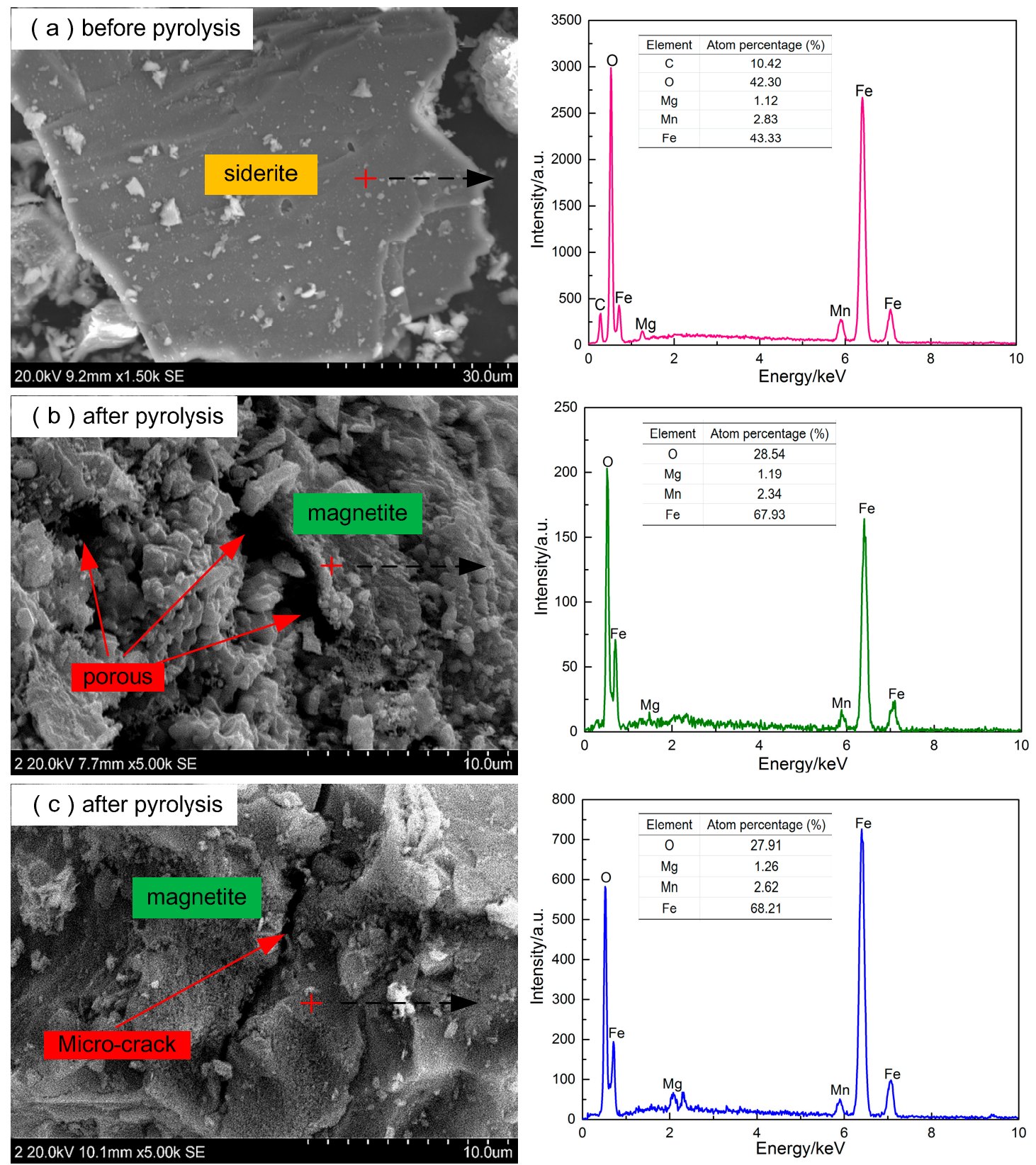

Figure 7. SEM and EDS analysis results of siderite before (a) and after $(\mathbf{b}, \mathbf{c})$ pyrolysis.

As illustrated in Figure 8, before pyrolysis, with the increase of magnetization magnetic intensity (MMI), magnetization intensity (MI) and specific susceptibility (SS) remained extremely low values; basically, it is suggested that the siderite exhibited a weakly magnetic mineral. After pyrolysis, as the MMI increased, the MI increased rapidly and then plateaued, reaching the magnetic saturation. Meanwhile, the SS briefly increased initially but decreased subsequently. A maximum of SS of $0.74 \times 10^{-3} \mathrm{~m}^{3} \cdot \mathrm{kg}^{-1}$ was observed at the MMI of $32.87 \mathrm{kA} \cdot \mathrm{m}^{-1}$. Because the MMI was lowered, magnetic domain wall in magnetite shifted rapidly with the increase of MMI, and magnetic moment turned to the magnetic field, until it reached magnetic saturation. When MMI increased further, the SS decreased gradually because the magnetic moment was essentially constraint. Therefore, the weakly magnetic siderite was transformed into strongly magnetic magnetite by pyrolysis, and the SS of sample improved significantly. In other words, the pyrolysis process expanded the difference of magnetic properties between iron mineral and gangue minerals, facilitating their effective separation in the subsequent low intensity magnetic separation. 


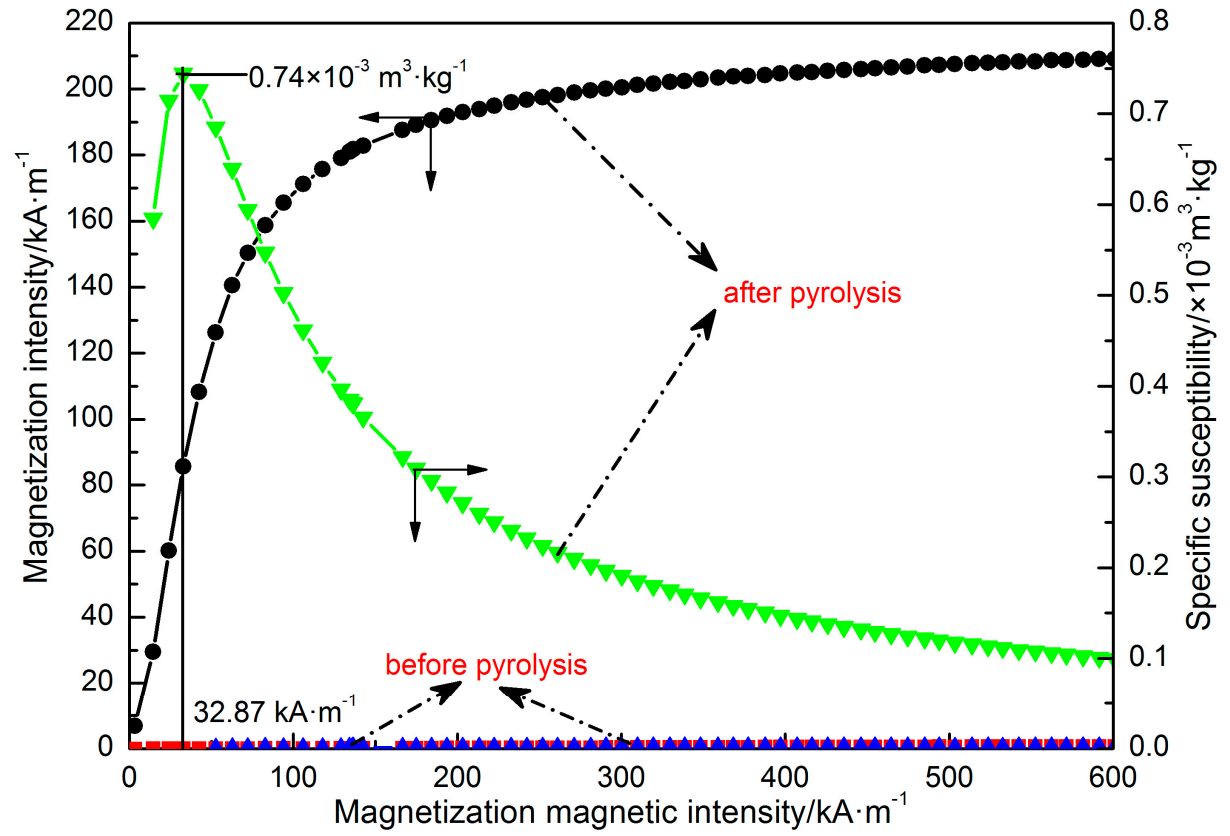

Figure 8. Magnetic analysis of the siderite before and after pyrolysis.

\section{Conclusions}

The pyrolysis behavior and kinetics of siderite at different heating rates were investigated using thermogravimetry technique and laboratory type tube furnace.

(1) With the increase of heating rate, the TG and DTG curves shifted to higher temperatures. The starting temperatures, maximum weight loss rate and ending temperature increased, and the pyrolysis temperature range became wider. However, heating rate had little effect on the total mass loss. The siderite pyrolysis was one-step reaction and an intense endothermic process. A higher pyrolysis rate could be achieved in a relatively short period of time by increasing of heating rate in a certain range.

(2) At heating rates of $5,10,20$ and $30{ }^{\circ} \mathrm{C} \cdot \mathrm{min}^{-1}$, the pyrolysis kinetics of siderite in neutral atmosphere was consistent with $\mathrm{A}_{1 / 2}$ (nucleation and growth) mechanism function. The forms of integral and differential mechanism functions were $G(\alpha)=[-\ln (1-\alpha)]^{-2}$ and $f(\alpha)=1 / 2(1-\alpha)[-\ln (1-\alpha)]^{-1}$, respectively. The corresponding activation energies were $446.13,469.10,487.89$, and $505.19 \mathrm{~kJ} \cdot \mathrm{mol}^{-1}$ and the pre-exponential factors were $6.67 \times 10^{-18}, 1.75 \times 10^{-19}, 1.80 \times 10^{-20}$, and $2.40 \times 10^{-21} \mathrm{~min}^{-1}$, indicating an increasing trend with heating rate increase. The heating rate plays a vital role in controlling siderite pyrolysis.

(3) The weakly magnetic siderite was transformed into ferromagnetic magnetite after pyrolysis. The surface of the newly formed magnetite was porous with micro-cracks. Mn and Mg remained in the samples during pyrolysis. The magnetization intensity and specific susceptibility enhanced significantly, which was beneficial to further enrichment and utilization of iron minerals.

Acknowledgments: The authors are grateful for the financial support provided by the National Natural Science Foundation of China (No. 51674064) and the Fundamental Research Funds for the Central Universities of China (No. N160104007).

Author Contributions: Xiaolong Zhang and Yuexin Han conceived and designed the experiments; Xiaolong Zhang and Yongsheng Sun performed the experiments; Xiao long Zhang and Yanjun Li analyzed the data; and Xiaolong Zhang wrote the paper.

Conflicts of Interest: The authors declare no conflict of interest. 


\section{References}

1. Ponomar, V.P.; Dudchenko, N.O.; Brik, A.B. Phase transformations of siderite ore by the thermomagnetic analysis data. J. Magn. Magn. Mater. 2017, 423, 373-378. [CrossRef]

2. Zhu, D.; Zhao, Q.; Qiu, G. Magnetizing roasting magnetic separation of limonite ores from Anhui province in east China. J. Univ. Sci. Technol. B 2010, 32, 713-718.

3. Li, C.; Sun, H.; Bai, J.; Li, L. Innovative methodology for comprehensive utilization of iron ore tailings: Part 1 . The recovery of iron from iron ore tailings using magnetic separation after magnetizing roasting. J. Hazard. Mater. 2010, 174, 71-77. [CrossRef] [PubMed]

4. Srivastava, U.; Kawatra, S.K. Strategies for processing low-grade iron ore minerals. Miner. Process. Extr. Metall. Rev. 2009, 30, 361-371. [CrossRef]

5. Lin, G.; Zhang, L.; Peng, J.; Hu, T.; Yang, L. Microwave roasting of siderite and the catalytic combustion effects on anthracite. Appl. Therm. Eng. 2017, 117, 668-674. [CrossRef]

6. Xing, B.; Chen, T.; Cheng, S.; Liu, H.; Xie, Q.; Xie, J. Structural characteristic of natural siderite during thermal treatment. J. Chin. Ceram. Soc. 2016, 44, 1207-1212.

7. Vusikhis, A.S.; Leont'Ev, L.I.; Kudinov, D.Z.; Gulyakov, V.S. Metallization of siderite ore in reducing roasting. Russ. Metall. 2016, 2016, 404-408. [CrossRef]

8. Zhu, D.; Zhou, X.; Pan, J.; Luo, Y. Direct reduction and beneficiation of a refractory siderite lump. Miner. Process. Extr. Metall. Rev. 2014, 123, 246-250. [CrossRef]

9. Bai, S.J.; Meng, W.; Chao, L.; Wen, S.M. Microstructure Characteristic and Phase Evolution of Refractory Siderite Ore during Sodium-carbonate-added Catalyzing Carbothermic Reduction. J. Iron Steel Res. 2016, 23, 891-899. [CrossRef]

10. Luo, Y.H.; Zhu, D.Q.; Pan, J.; Zhou, X.L. Thermal decomposition behaviour and kinetics of Xinjiang siderite ore. Miner. Process. Extr. Metall. Rev. 2016, 125, 17-25. [CrossRef]

11. Gallagher, P.K.; West, K.W.; Warne, S.S.J. Use of the Mössbauer effect to study the thermal decomposition of sidewire. Therm. Acta 1981, 50, 41-47. [CrossRef]

12. Chang, Y.A.; Ahmad, N. Thermodynamic data on metal carbonates and related oxides. Metall. Soc. AIME 1982, 21, 94-100.

13. Dhupe, A.P.; Gokarn, A.N. Studies in the thermal decomposition of natural siderites in the presence of air. Int. J. Miner. Process. 1990, 28, 209-220. [CrossRef]

14. Geva, S.; Farren, M.; John, D.H.S.; Hayes, P.C. The effects of impurity elements on the reduction of wustite and magnetite to iron in $\mathrm{CO} / \mathrm{CO}_{2}$, and $\mathrm{H}_{2} / \mathrm{H}_{2} \mathrm{O}$ gas mixtures. Metall. Mater. Trans. B 1990, 21, 743-751. [CrossRef]

15. Goldin, D.M.; Kulikova, G.V. On the dissociation mechanism of carbonates and their isomorphous mixture. J. Therm. Anal. Calorim. 1984, 29, 139-145. [CrossRef]

16. Pan, Y.X.; Lin, M.; Hao, J.Q. Rock-magnetic properties related to thermal mineral alterations in siderite samples. Chin. J. Geophys. 1999, 42, 756-763.

17. Chen, C.; Zhang, Y.S.; Yang, Q. Thermokinetic study on magnetic roasting of refractory iron ore. Conserv. Util. Miner. Resour. 2013, 23, 31-34.

18. Dubrawski, J.V. Thermal decomposition of some siderite-magnesite minerals using DSC. J. Therm. Anal. Calorim. 1991, 37, 1213-1221. [CrossRef]

19. Gallagher, P.K.; Warne, S.S.J. Application of thermomagnetometry to the study of siderite. Mater. Res. Bull. 1981, 16, 141-144. [CrossRef]

20. Jagtap, S.B.; Pande, A.R.; Gokarn, A.N. Kinetics of thermal decomposition of siderite: Effect of particle size. Int. J. Miner. Process. 1992, 36, 113-124. [CrossRef]

21. Gotor, F.J.; Macías, M.; Ortega, A.; Criado, J.M. Comparative study of the kinetics of the thermal decomposition of synthetic and natural siderite samples. Phys. Chem. Miner. 2000, 27, 495-503. [CrossRef]

22. He, W. The Basic Research on Magnetizing Roasting-Magnetic Separation of Siderite. Ph.D. Thesis, Central South University, Changsha, China, 2012.

23. Feng, Z.L.; Yu, Y.F.; Liu, G.F.; Chen, W.; Lv, G. Thermal decomposition kinetics of siderite ore in suspension condition. Chin. J. Process. Eng. 2012, 12, 427-432.

24. Huang, M.X.; Zhou, C.R.; Han, X.W. Investigation of thermal decomposition kinetics of taurine. J. Therm. Anal. Calorim. 2013, 113, 589-593. [CrossRef] 
25. Otero, M.; Calvo, L.F.; Gil, M.V.; Garc'1a, A.I.; Mora'n, A. Co-combustion of different sewage sludge and coal: A non-isothermal thermogravimetric kinetic analysis. Bioresour. Technol. 2008, 99, 6311-6319. [CrossRef] [PubMed]

26. Janković, B.; Adnađević, B.; Mentus, S. The kinetic analysis of non-isothermal nickel oxide reduction in hydrogen atmosphere using the invariant kinetic parameters method. Thermochim. Acta 2007, 456, 48-55. [CrossRef]

27. Vyazovkin, S.; Burnham, A.K.; Criado, J.M.; Pérez-Maqueda, L.A.; Popescu, C.; Sbirrazzuoli, N. ICTAC Kinetics Committee recommendations for performing kinetic computations on thermal analysis data. Thermochim. Acta 2011, 520, 1-19. [CrossRef]

28. Guinesi, L.S.; Ribeiro, C.A.; Crespi, M.S.; Veronezi, A.M. Tin(II) EDTA complex: Kinetic of thermal decomposition by non-isothermal procedures. Thermochim. Acta 2004, 414, 35-42. [CrossRef]

29. Jankovic, B.; Mentus, S. Model-fitting and model-free analysis of thermal decomposition of palladium acetylacetonate [Pd (acac) $)_{2}$. J. Therm. Anal. Calorim. 2008, 94, 395-403. [CrossRef]

30. Wu, D.; Liu, G.; Chen, S.; Sun, R. An experimental investigation on heating rate effect in the thermal behavior of perhydrous bituminous coal during pyrolysis. J. Therm. Anal. Calorim. 2015, 119, 2195-2203. [CrossRef]

31. Sun, Y.; Han, Y.; Wei, X.; Gao, P. Non-isothermal reduction kinetics of oolitic iron ore in ore/coal mixture. J. Therm. Anal. Calorim. 2016, 123, 703-715. [CrossRef]

32. Polli, H.; Pontes, L.A.M.; Araujo, A.S. Application of model-free kinetics to the study of thermal degradation of polycarbonate. J. Therm. Anal. Calorim. 2005, 79, 383-387. [CrossRef]

33. Lin, Y.K.; Li, Q.S.; Li, X.F.; Ji, K.; Zhang, H.P.; Yu, Y.M.; Song, Y.H.; Fu, Y.; Sun, L.Y. Pyrolysates distribution and kinetics of Shenmu long flame coal. Energy Convers. Manag. 2014, 86, 428-434. [CrossRef]

34. Doyle, C.D. Series approximations to the equations of thermogravimetric data. Nature 1965, 207, $290-291$. [CrossRef]

35. Škvára, F.; Šesták, J. Computer calculation of the mechanism and associated kinetic data using a non-isothermal integral method. J. Therm. Anal. 1975, 8, 477-489. [CrossRef]

36. Hu, R.Z.; Shi, Q.Z. Thermal Analysis Kinetics, 2nd ed.; Science Press: Beijing, China, 2008.

37. Li, P.; Yu, Q.B.; Xie, H.Q.; Qin, Q.; Wang, K. $\mathrm{CO}_{2}$ gasification rate analysis of Datong coal using slag granules as heat carrier for heat recovery from blast furnace slag by using a chemical reaction. Energy Fuels 2013, 27, 4810-4817. [CrossRef]

38. Vlaev, L.T.; Markovska, I.G.; Lyubchev, L.A. Non-isothermal kinetics of pyrolysis of rice husk. Thermochim. Acta 2003, 406, 1-7. [CrossRef]

39. Li, P.; Yu, Q.B.; Qin, Q.; Lei, W. Kinetics of $\mathrm{CO}_{2} /$ coal gasification in molten blast furnace slag. Ind. Eng. Chem. Res. 2012, 51, 15872-15883. [CrossRef]

(c) 2017 by the authors. Licensee MDPI, Basel, Switzerland. This article is an open access article distributed under the terms and conditions of the Creative Commons Attribution (CC BY) license (http://creativecommons.org/licenses/by/4.0/). 